\title{
Outcome of percutaneous coronary intervention with the Absorb bioresorbable scaffold: data from the Swedish Coronary Angiography and Angioplasty Registry (SCAAR)
}

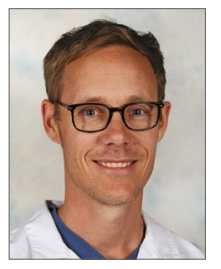

Per Grimfjärd ${ }^{1,2 *}, \mathrm{MD}$; Stefan James ${ }^{1,3}, \mathrm{MD}, \mathrm{PhD}$; Jonas Persson ${ }^{4}, \mathrm{MD}, \mathrm{PhD}$; Oskar Angerås ${ }^{5}, \mathrm{MD}, \mathrm{PhD}$; Sasha Koul ${ }^{6}, \mathrm{MD}, \mathrm{PhD}$; Elmir Omerovic ${ }^{5}, \mathrm{MD}, \mathrm{PhD}$; Christoph Varenhorst ${ }^{1,3}, \mathrm{MD}, \mathrm{PhD}$; Bo Lagerqvist $\mathrm{t}^{1,3}, \mathrm{MD}$, PhD; David Erlinge ${ }^{6}, \mathrm{MD}, \mathrm{PhD}$

1. Department of Medical Sciences, Cardiology, Uppsala University, Uppsala, Sweden; 2. Department of Cardiology, Västerås Hospital, Västerås, Sweden; 3. Uppsala Clinical Research Center, Uppsala University Hospital and Uppsala University, Uppsala, Sweden; 4. Department of Cardiology, Danderyd Hospital, Stockholm, Sweden; 5. Department of Cardiology, Sahlgrenska University Hospital, Gothenburg, Sweden; 6. Department of Cardiology, Clinical Sciences, Lund University, Skåne University Hospital, Lund, Sweden

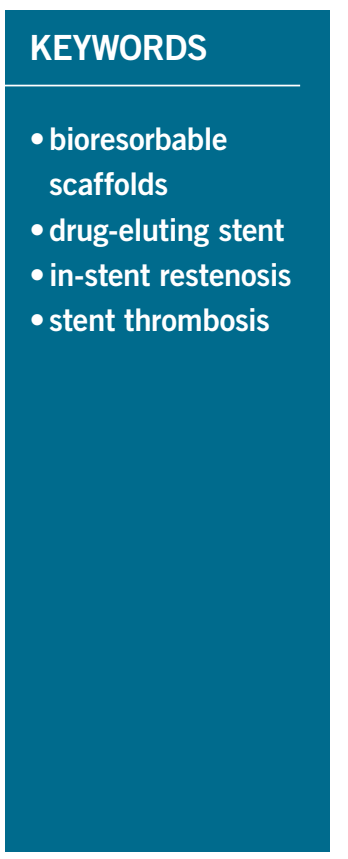

\begin{abstract}
Aims: Randomised trials indicate higher rates of stent thrombosis (ST) and target lesion failure (TLF) after percutaneous coronary intervention (PCI) with the Absorb bioresorbable scaffold (BRS) compared with modern drug-eluting stents (DES). We aimed to investigate the outcome of all Swedish patients treated with the Absorb BRS.

Methods and results: The Absorb BRS $(\mathrm{n}=810)$ was compared with commonly used modern DES $(\mathrm{n}=67,909)$. The main outcome measure was definite ST; mean follow-up was two years. Despite being implanted in a younger, lower-risk population compared with modern DES, the Absorb BRS was associated with a higher crude incidence of definite ST at stent level: 1.5 vs. $0.6 \%$, hazard ratio (HR) 2.38 (95\% confidence interval [CI]: 1.34-4.23), adjusted HR 4.34 (95\% CI: 2.37-7.94); $\mathrm{p}<0.001$. The patient level adjusted HR was 4.44 (95\% CI: 2.25-8.77). Rates of in-stent restenosis were similar for BRS and DES. Non-compliance with dual antiplatelet therapy (DAPT) guidelines was noted in six out of 12 BRS ST events. Three very late ST events occurred with the Absorb BRS.
\end{abstract}

Conclusions: In this real-world observational study, the Absorb BRS was associated with a significantly higher risk of definite ST compared with modern DES. Non-compliance with DAPT guideline recommendations was common among Absorb definite ST events.

\footnotetext{
*Corresponding author: Department of Medical Sciences, Cardiology, Uppsala University, 75236 Uppsala, Sweden. E-mail:per.grimfjard@ucr.uu.se
} 


\section{Abbreviations}

$\begin{array}{ll}\text { AMI } & \text { acute myocardial infarction } \\ \text { BRS } & \text { bioresorbable scaffold } \\ \text { CABG } & \text { coronary artery bypass graft } \\ \text { DAPT } & \text { dual antiplatelet therapy } \\ \text { DES } & \text { drug-eluting stent } \\ \text { FFR } & \text { fractional flow reserve } \\ \text { GP IIb/IIla } & \\ \text { inhibitor } & \text { glycoprotein IIb/IIIa inhibitor } \\ \text { iFR } & \text { instantaneous wave-free ratio } \\ \text { ISR } & \text { in-stent restenosis } \\ \text { IVUS } & \text { intravascular ultrasound } \\ \text { LAD } & \text { left anterior descending } \\ \text { LCX } & \text { left circumflex } \\ \text { RCA } & \text { right coronary artery } \\ \text { NSTEMI } & \text { non-ST-segment elevation myocardial infarction } \\ \text { OCT } & \text { optical coherence tomography } \\ \text { PCI } & \text { percutaneous coronary intervention } \\ \text { SCAAR } & \text { Scandinavian Coronary Angiography and Angioplasty } \\ & \text { Registry } \\ \text { ST } & \text { stent thrombosis } \\ \text { STEMI } & \text { ST-segment elevation myocardial infarction } \\ \text { TLF } & \text { target lesion failure } \\ & \end{array}$

\section{Introduction}

Modern drug-eluting stents (DES) have improved outcomes in patients treated with percutaneous coronary intervention (PCI), compared with older-generation DES and bare metal stents ${ }^{1}$. Issues remain with in-stent restenosis (ISR), stent thrombosis (ST), neoatherosclerosis and altered endothelial function. A recent randomised clinical trial (RCT) reported rates of revascularisation of $16.5 \%$ with a median of five years of follow-up after PCI with modern $\mathrm{DES}^{2}$. Rates of ST are around $1 \%$ over two years with modern DES and ST often causes ST-elevation myocardial infarction (STEMI) with substantial morbidity ${ }^{3,4}$.

Given ISR and ST, the concept of a bioresorbable scaffold (BRS) is appealing. The Absorb ${ }^{\mathrm{TM}}$ BRS (Abbott Vascular, Santa Clara, CA, USA), introduced in Sweden in 2011, has been extensively studied in randomised clinical trials and registries and implanted in more than 150,000 patients. One- and two-year data from randomised trials comparing the Absorb BRS and metallic everolimus-eluting DES showed similar results for composite clinical and device-oriented endpoints 5 . However, with longer follow-up there has been increasing concern about excess risk of target lesion failure (TLF) and ST, particularly the issue of very late $\mathrm{ST}^{6,7}$.

The aim of this study was to investigate the outcome of patients treated with the Absorb BRS in Sweden in relation to commonly used modern DES. We further investigated all BRS ST events in detail to identify factors of importance.

\section{Editorial, see page 1259}

\section{Methods}

This was a retrospective analysis from the prospective Swedish Coronary Angiography and Angioplasty Registry (SCAAR), part of the Swedish Web-system for enhancement and development of evidence-based care in heart disease (SWEDEHEART) registry, described elsewhere ${ }^{8}$. SCAAR includes all Swedish patients undergoing a diagnostic catheterisation or PCI procedure, currently 40,000 patients yearly. The performing physician enters clinical data, detailed angiographic findings, procedures, technical specifications and pharmacological treatment. Occurrence of definite ST and ISR is actively recorded by mandatory questions for every previously implanted stent at the time of any subsequent coronary angiography.

All patients treated with the Absorb BRS or any of the twelve most commonly used modern DES between 2011 and August 2016 were included. Mean follow-up time was two years. Patients treated by physicians/hospitals without Absorb experience were excluded to obtain a fair comparison, concentrating on the same interventionists. Cardiogenic shock patients were excluded $(n=645)$ as were all DES implanted in sizes $<2.5 \mathrm{~mm}$, since Absorb is unavailable in such dimensions. Absorb BRS were compared with pooled modern DES (Figure 1).

The primary outcome measure was incidence of definite ST, corresponding with the Academic Research Consortium definition ${ }^{9}$. The secondary outcome measure was incidence of ISR, defined in SCAAR as $70 \%$ stenosis or positive fractional flow reserve/instantaneous wave-free ratio $(\mathrm{FFR} / \mathrm{iFR})$ as per judgement by the operator. We also analysed all-cause mortality and rates of myocardial infarction at one year from index PCI. Stable angina, unstable angina, non-ST-elevation myocardial infarction (NSTEMI) and ST-elevation myocardial infarction (STEMI) are defined in SCAAR in accordance with ESC guidelines ${ }^{10}$.

In addition to SCAAR data, all BRS ST events were analysed by reviewing films and medical charts, obtaining more detailed information on implantation technique and timing of antithrombotic medications. This study complies with the Declaration of Helsinki. Ethics board approval was obtained from the Lund local ethics committee (reference 2015/297).

\section{STATISTICAL ANALYSIS}

The main analysis was stent level, performed on the total stent cohort. Three sensitivity analyses were performed.

\section{Main analysis (1) and sensitivity analyses (2-4)}

1. Total stent cohort. Stent level analysis on all Absorb BRS and commonly used modern DES.

2. Single stent cohort. Stent level analysis on patients treated with only one single Absorb BRS or DES.

3. Patient level cohort. Only one ST or ISR event was counted per patient. Patients treated with both Absorb BRS and DES were excluded, meaning that the groups being compared were $100 \%$ Absorb BRS and 100\% DES.

4. Propensity score-matched analysis. Patient level.

Continuous variables were expressed as means and discrete variables as percentages. Adjusted analyses were performed using propensity score and Cox regression to adjust for baseline differences. Two different propensity scores were created for stent and patient level analyses. The different propensity scores were 


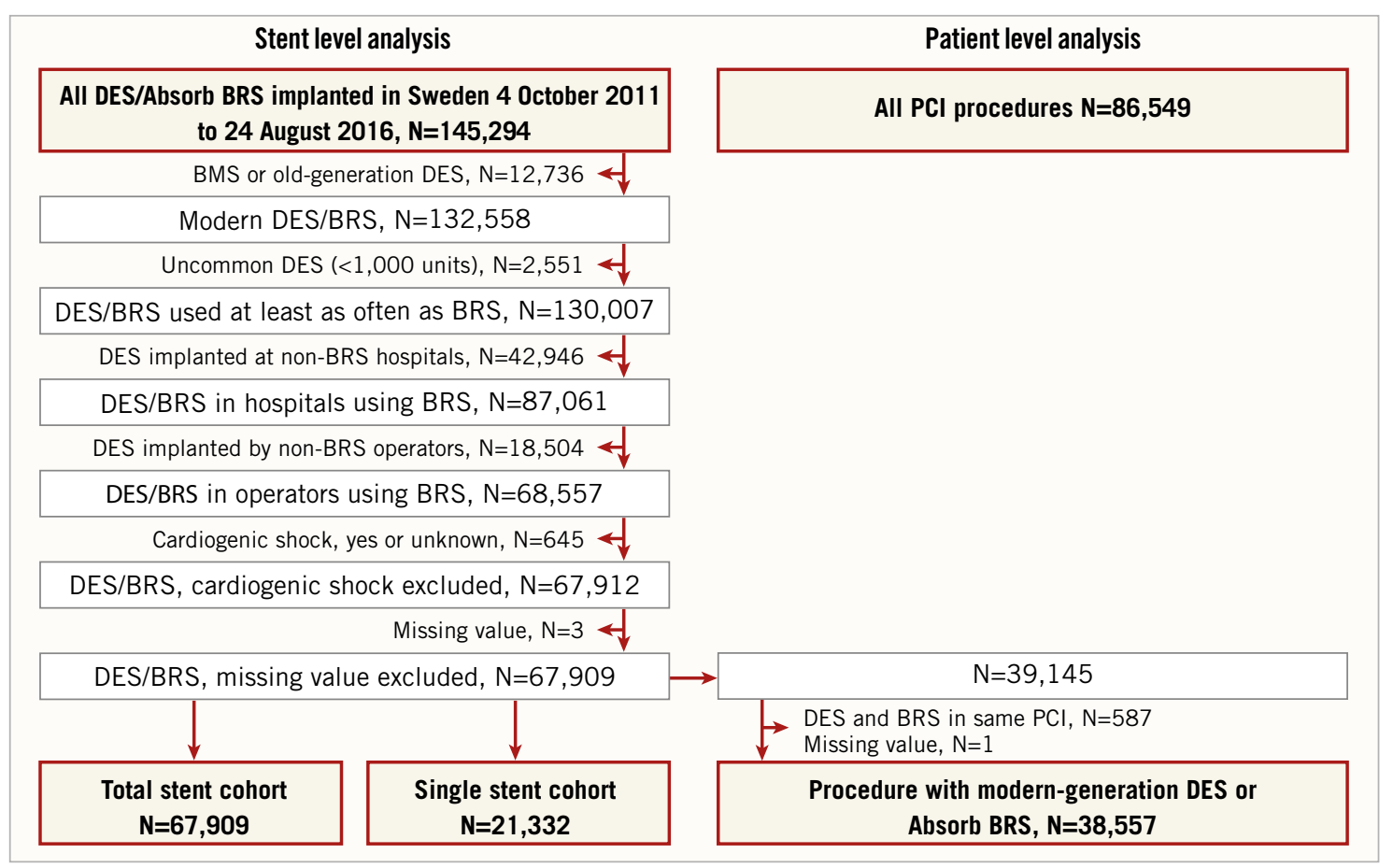

Figure 1. Flow chart. Flow chart indicating patient selection and exclusion. BMS: bare metal stent; BRS: Absorb bioresorbable scaffold; DES: drug-eluting stent

then added in two different Cox regression models, one for stent and one for patient level analysis. Propensity score variables were selected a priori based on clinical relevance.

1. Stent level propensity score variables: year of PCI, treating hospital, age at PCI, gender, indication for PCI, diabetes, smoking status, hyperlipidaemia, hypertension, previous AMI, previous PCI, previous $\mathrm{CABG}$, treated vessel, number of stents, stent diameter and length, lesion grading (A, B1, B2, C), bifurcation lesion, restenotic lesion, chronic occlusion, extent of coronary disease at angiogram (1, 2 or 3-vessel disease with/without left main involvement), aspirin before PCI, P2 $\mathrm{Y}_{12}$ inhibitor before PCI, anticoagulation before PCI, oral anticoagulation before PCI.

2. Patient level propensity score variables: multivessel PCI, graft PCI and post-dilation were added to all variables listed above for the stent level propensity score.

The propensity scores were subsequently used as covariates in two different Cox regression models for stent and patient level analyses. Additional covariates in the Cox model were selected based on clinical relevance and the fact that they occurred after the stent selection process.

1. Stent level Cox model covariates: stent level propensity score, complete revascularisation, GP IIb/IIIa inhibitor treatment during PCI, general success of procedure, post-dilation, dilation pressure, optical coherence tomography (OCT), and intravascular ultrasound (IVUS).

2. Patient level Cox model covariates: patient level propensity score plus all covariates listed for the stent level Cox model except stent level propensity score.
All reported p-values are two-sided. All analyses were performed using SPSS statistical software, Version 19.0 (IBM Corp., Armonk, NY, USA).

\section{Results \\ BACKGROUND DATA}

The background and procedural data of the study population, at patient level, are presented in Table 1. In summary, BRS were implanted in a substantially younger (59 vs. 68 years) and lowerrisk population. The clinical indication for BRS implantation was less often STEMI and more often stable coronary artery disease compared with the DES-treated patients. In general, BRS was implanted in a population with less advanced coronary disease and in less complicated target lesions. Slightly more intravascular imaging (13.1\% vs. $5.1 \%)$ and more frequent post-dilatation $(63 \%$ vs. $35 \%$ ) was used for BRS implantation compared with DES.

\section{STENT THROMBOSIS}

The total number of patients with definite ST was 330, 11 with BRS. The total number of stents with ST was 418,12 in BRS.

In the total stent cohort, there were 12 cases of ST (12/810) in Absorb BRS compared with 406/67,909 with modern DES. The Absorb BRS was associated with a significantly higher crude incidence of ST: 1.5 vs. $0.6 \%$, hazard ratio (HR) 2.38 (95\% confidence interval [CI]: 1.34-4.23) and adjusted HR $4.34(95 \%$ CI: $2.37-7.94) ; \mathrm{p}<0.001$. Results were consistent in magnitude and direction in all three sensitivity analyses: in the single stent cohort: 2.4 vs. $0.6 \%$, adjusted HR 7.88 (95\% CI: 3.53-17.60) and 
Table 1. Background and procedural data, patient level.

\begin{tabular}{|c|c|c|}
\hline & $\begin{array}{c}\text { DES } \\
(\mathrm{N}=38,097)\end{array}$ & $\begin{array}{c}\text { Absorb BRS } \\
(\mathrm{N}=460)\end{array}$ \\
\hline Male sex (\%) & 74.8 & 79.3 \\
\hline Age at $\mathrm{PCl}$, years, mean & 67.8 & 59.3 \\
\hline Body weight, kg, mean & 82.8 & 85.7 \\
\hline \multicolumn{3}{|l|}{ Indication } \\
\hline Stable angina & $24.5 \%$ & $25 \%$ \\
\hline STEMI & $24.7 \%$ & $21.3 \%$ \\
\hline UA & $10.4 \%$ & $11.3 \%$ \\
\hline NSTEMI & $36.1 \%$ & $39.6 \%$ \\
\hline Other & $4.3 \%$ & $2.8 \%$ \\
\hline \multicolumn{3}{|l|}{ Risk factors } \\
\hline Statin treatment & $53.6 \%$ & $40.2 \%$ \\
\hline Antihypertensive treatment & $64.9 \%$ & $48 \%$ \\
\hline Never smoked & $38.4 \%$ & $41.7 \%$ \\
\hline Current smoker & $18.3 \%$ & $21.1 \%$ \\
\hline Diabetes without insulin & $11.8 \%$ & $7.0 \%$ \\
\hline Diabetes with insulin & $10.6 \%$ & $9.3 \%$ \\
\hline Previous AMI & $28.7 \%$ & $16.3 \%$ \\
\hline Previous PCI & $30.4 \%$ & $17.4 \%$ \\
\hline Previous CABG & $9.4 \%$ & $2.0 \%$ \\
\hline Creatinine, mean, umol/L & 89 & 81 \\
\hline \multicolumn{3}{|l|}{ Procedural data } \\
\hline General success & $98.2 \%$ & $98.9 \%$ \\
\hline Post-dilation yes & $35 \%$ & $63 \%$ \\
\hline IVUS used & $3.8 \%$ & $5.7 \%$ \\
\hline OCT used & $1.3 \%$ & $7.4 \%$ \\
\hline Any bifurcation treated at $\mathrm{PCl}$ & $21.5 \%$ & $18.3 \%$ \\
\hline CTO treated at $\mathrm{PCl}$ & $6.6 \%$ & $2.6 \%$ \\
\hline Restenotic lesion treated & $6.6 \%$ & $1.5 \%$ \\
\hline Direct stenting & $27.2 \%$ & $19.3 \%$ \\
\hline Local success & $99 \%$ & $99.1 \%$ \\
\hline Non-office hours & $25.6 \%$ & $25.0 \%$ \\
\hline
\end{tabular}

in the patient level cohort: 2.2 vs. $0.8 \%$, adjusted HR $4.44(95 \%$ CI: 2.25-8.77) (Table 2, Figure 2A-Figure 2C).

\section{IN-STENT RESTENOSIS (EXCLUDING STENT THROMBOSIS)}

The total number of patients with ISR was 785, six with Absorb BRS. The total number of stents with ISR was 1,016, 11 with BRS. The crude incidence of ISR did not differ significantly

\begin{tabular}{|c|c|c|}
\hline & $\begin{array}{c}\text { DES } \\
(\mathrm{N}=38,097)\end{array}$ & $\begin{array}{c}\text { Absorb BRS } \\
(\mathrm{N}=460)\end{array}$ \\
\hline \multicolumn{3}{|l|}{ Procedural data } \\
\hline No. of stents, mean & 1.77 & 1.37 \\
\hline Min. stent diameter, mm, mean & 3.0 & 3.25 \\
\hline Mean diameter of stents used, $\mathrm{mm}$ & 3.07 & 3.28 \\
\hline Total stent length, mm, mean & 36.9 & 26.9 \\
\hline \multicolumn{3}{|l|}{ Vessel treated } \\
\hline $\mathrm{RCA}$ & $32.2 \%$ & $23.5 \%$ \\
\hline LM & $6.1 \%$ & $0.2 \%$ \\
\hline LAD & $44 \%$ & $63.3 \%$ \\
\hline LCX & $14.9 \%$ & $12.4 \%$ \\
\hline Arterial graft & $0.1 \%$ & 0 \\
\hline Vein graft & $2.8 \%$ & $0.7 \%$ \\
\hline Any graft & $3.2 \%$ & $0.7 \%$ \\
\hline Multivessel & $25.3 \%$ & $12.6 \%$ \\
\hline \multicolumn{3}{|l|}{ Severity of disease } \\
\hline 1 vessel & $46.7 \%$ & $75.7 \%$ \\
\hline 2 vessels & $29 \%$ & $18.7 \%$ \\
\hline 3 vessels & $16.5 \%$ & $5.0 \%$ \\
\hline LM & $7.2 \%$ & $0.2 \%$ \\
\hline \multicolumn{3}{|l|}{ Pharmacology at PCI } \\
\hline UFH & $72.6 \%$ & $84.1 \%$ \\
\hline LMWH & $4.7 \%$ & $2.2 \%$ \\
\hline Bivalirudin & $21.8 \%$ & $12.8 \%$ \\
\hline \multicolumn{3}{|c|}{$\begin{array}{l}\text { "General success" and "local success" arbitrarily defined by the physician } \\
\text { performing the intervention, by mandatory questions. AMI: acute } \\
\text { myocardial infarction; BRS: bioresorbable scaffold; CABG: coronary artery } \\
\text { bypass grafting; CTO: chronic total occlusion; DES: drug-eluting stent; } \\
\text { IVUS: intravascular ultrasound; LAD: left anterior descending coronary } \\
\text { artery; LCX: left circumflex coronary artery; LM: left main coronary artery; } \\
\text { LMWH: low molecular weight heparin; Min.: minimum; No.: number; } \\
\text { NSTEMI: non-ST-elevation myocardial infarction; OCT: optical coherence } \\
\text { tomography; PCI: percutaneous coronary intervention; RCA: right coronary } \\
\text { artery; STEMI: ST-elevation myocardial infarction; UA: unstable angina; } \\
\text { UFH: unfractionated heparin }\end{array}$} \\
\hline
\end{tabular}

between BRS and DES: 1.4 vs. 1.5\%, HR 0.88 (95\% CI: $0.41-$ 1.92), adjusted HR 1.03 (95\% CI: 0.56-1.92); $\mathrm{p}=0.903$. Results were consistent in all three sensitivity analyses (Table 3, Figure 3).

\section{MORTALITY AND MYOCARDIAL INFARCTION}

The crude rates of all-cause mortality at one year were $1.0 \%$ in the BRS group and $5.0 \%$ in the DES group. The crude rates of

Table 2. Outcome: stent thrombosis.

\begin{tabular}{|l|c|c|c|c|c|c|c|} 
& Cohort & $\begin{array}{c}\text { Absorb BRS } \\
\text { Events/N }\end{array}$ & DES Events/N & $\begin{array}{c}\text { Unadjusted HR } \\
(\mathbf{9 5 \%} \text { CI) }\end{array}$ & $\begin{array}{c}\text { Unadjusted } \\
\boldsymbol{p} \text {-value }\end{array}$ & $\begin{array}{c}\text { Adjusted HR } \\
(\mathbf{9 5 \%} \text { CI) }\end{array}$ & $\begin{array}{c}\text { Adjusted } \\
\boldsymbol{p} \text {-value }\end{array}$ \\
\hline $\begin{array}{l}\text { Main } \\
\text { analysis }\end{array}$ & Total stent & $12 / 810(1.5 \%)$ & $406 / 67,909(0.6 \%)$ & $2.38(1.28-4.45)$ & 0.006 & $4.34(2.35-8.00)$ & $<0.001$ \\
\hline $\begin{array}{l}\text { Sensitivity } \\
\text { analyses }\end{array}$ & Single stent & $8 / 336(2.4 \%)$ & $120 / 20,996(0.6 \%)$ & $3.96(1.94-8.10)$ & $<0.001$ & $7.88(3.53-17.60)$ & $<0.001$ \\
\cline { 2 - 8 } & Patient level & $10 / 460(2.2 \%)$ & $320 / 38,097(0.8 \%)$ & $2.50(1.33-4.69)$ & 0.004 & $4.44(2.25-8.77)$ & $<0.001$ \\
\cline { 2 - 8 } & PS matched & $12 / 790(1.5 \%)$ & $23 / 6,405(0.4 \%)$ & & & $4.22(2.02-8.82)$ & $<0.001$ \\
\hline
\end{tabular}


Table 3. Outcome: in-stent restenosis.

\begin{tabular}{|l|l|r|r|r|c|c|c|}
\hline & \multicolumn{1}{|c|}{ Cohort } & $\begin{array}{c}\text { Absorb BRS } \\
\text { Events/N }\end{array}$ & DES Events/N & $\begin{array}{c}\text { Unadjusted HR } \\
(\mathbf{9 5 \%} \text { CI) }\end{array}$ & $\begin{array}{c}\text { Unadjusted } \\
\boldsymbol{p} \text {-value }\end{array}$ & $\begin{array}{c}\text { Adjusted HR } \\
\text { (95\% CI) }\end{array}$ & $\begin{array}{c}\text { Adjusted } \\
\boldsymbol{p} \text {-value }\end{array}$ \\
\hline Main analysis & Total stent & $11 / 810(1.4 \%)$ & $1,005 / 67,909(1.5 \%)$ & $0.88(0.41-1.92)$ & 0.752 & $1.04(0.44-2.44)$ & 0.930 \\
\hline $\begin{array}{l}\text { Sensitivity } \\
\text { analyses }\end{array}$ & Single stent & $3 / 336(0.9 \%)$ & $312 / 20,996(1.5 \%)$ & $0.58(0.19-1.82)$ & 0.355 & $0.62(0.19-2.05)$ & 0.435 \\
\cline { 2 - 8 } & Patient level & $6 / 460(1.3 \%)$ & $779 / 38,097(2.0 \%)$ & $0.61(0.27-1.37)$ & 0.233 & $0.91(0.40-2.08)$ & 0.818 \\
\cline { 2 - 8 } & PS matched & $11 / 790(1.4 \%)$ & $74 / 6,405(1.2 \%)$ & & & $1.22(0.54-2.74)$ & 0.635 \\
\hline
\end{tabular}

A

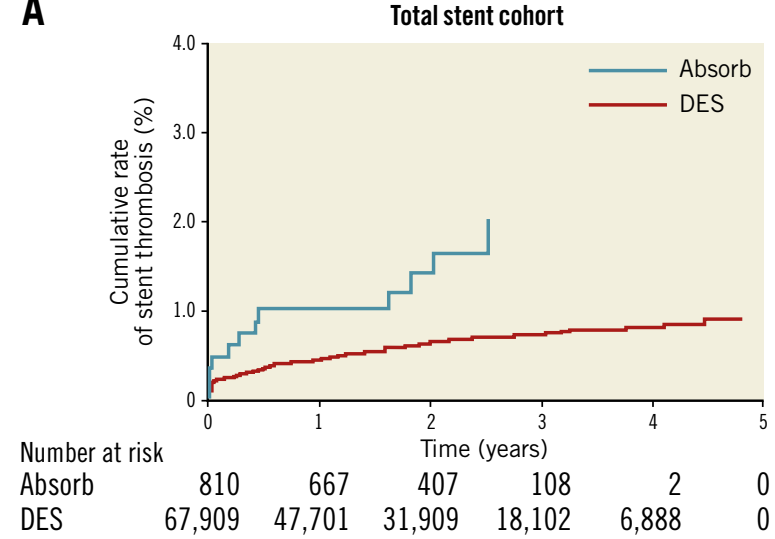

B

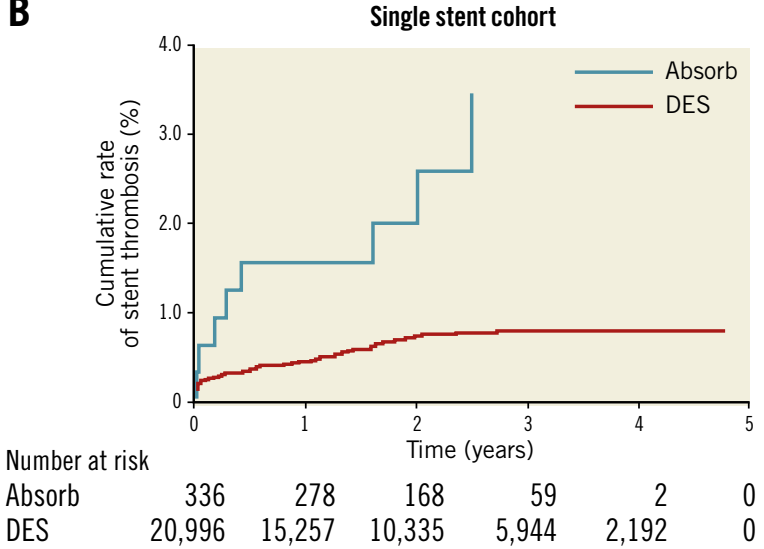

C

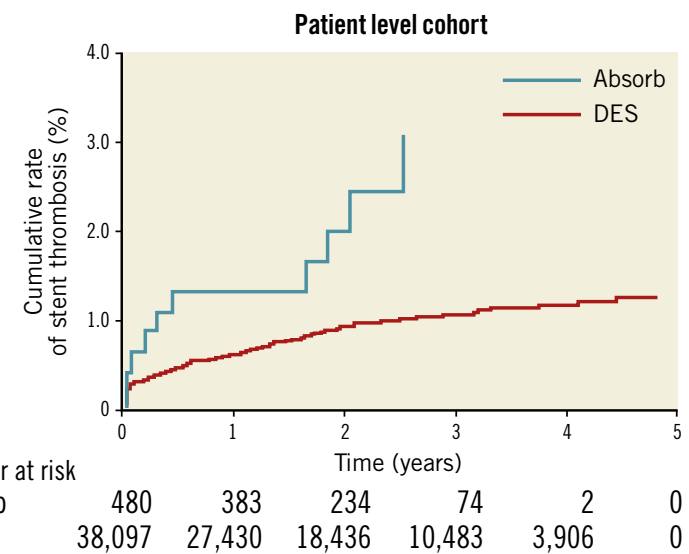

Figure 2. Kaplan-Meier event curves. A) Stent thrombosis in the total stent cohort. B) Stent thrombosis in the single stent cohort. C) Stent thrombosis in the patient level cohort. DES: drug-eluting stent reinfarction (any vessel) at one year were $3.0 \%$ in the BRS group and $3.8 \%$ in the DES group. These findings reflect the major baseline risk differences between the study groups.

\section{DETAILS OF ABSORB BRS DEFINITE ST EVENTS}

All Absorb BRS ST events were followed up at the local lab by interventionalists reviewing films and medical charts for both the index and ST event PCI. The timing of BRS ST events in relation to antithrombotic drug treatment is displayed in Figure 4. European guidelines recommend 12 months of dual antiplatelet therapy (DAPT) following acute coronary syndrome and six months of DAPT following PCI for stable angina9. Three BRS ST events occurred only days after index PCI due to patient discontinuation of the prescribed DAPT after hospital discharge. Non-compliance with DAPT guidelines (clopidogrel or ticagrelor and aspirin) was noted in a total of six BRS ST cases with the time lapsed from early DAPT discontinuation to the subsequent ST being 1, 2, 2, 2, 3 and 30 days, respectively. Very late ST after planned discontinuation was noted in three cases.

Post-dilation was used in 10 out of 12 BRS ST cases at implantation. Intravascular imaging was not used in any of the BRS ST cases at implantation. Undersizing of the BRS was noted in three patients (in retrospect). One ST occurred in a $3 \mathrm{~mm}$ Absorb BRS post-dilated with a $3.75 \mathrm{~mm}$ non-compliant balloon, possibly causing BRS fracture. Only one BRS ST occurred in a patient originally treated for stable angina; the rest of the BRS were implanted

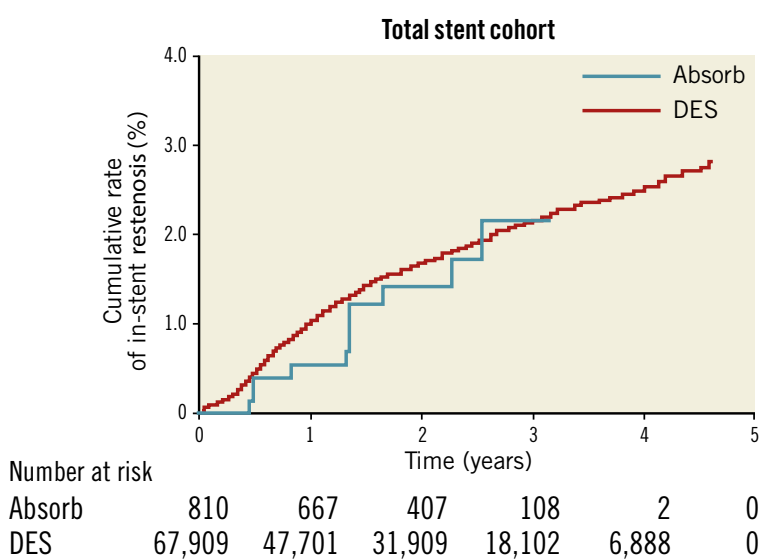

Figure 3. Kaplan-Meier event curve of in-stent restenosis, excluding stent thrombosis, in the total stent cohort. DES: drug-eluting stent 


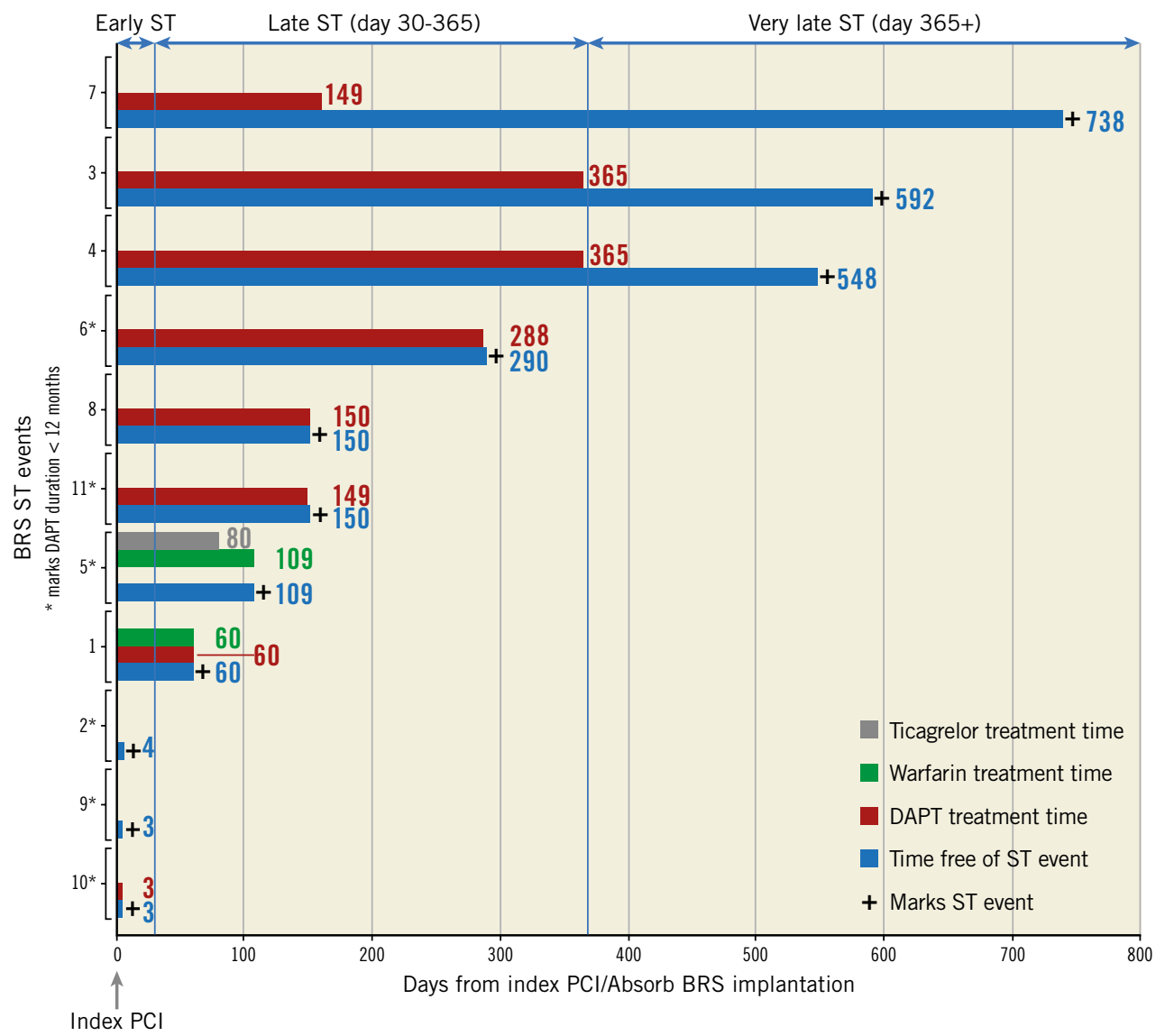

Figure 4. Timing of Absorb BRS stent thrombosis events and antithrombotic pharmacological treatment. X-axis shows time elapsed from index percutaneous coronary intervention (PCI) to stent thrombosis (ST) event (blue bars). + marks ST event. The duration of antithrombotic drug treatment in days is printed at end of bars. Y-axis shows the different ST events. * marks duration of dual antiplatelet therapy (DAPT) $<12$ months (as noted in six out of 11 events). Failure of initiation of DAPT was noted in three cases. At the top of the panel the blue arrows indicate time intervals for early, late and very late ST. BRS: Absorb bioresorbable scaffold

in acute coronary syndrome patients. While reassessing films, one event registered as BRS ST in SCAAR was, in retrospect, considered likely in-stent restenosis with acute presentation. No reclassification was made since a corresponding in-depth analysis of the DES ST events was not performed. Two BRS ST events were registered and counted in the same patient and PCI as the physician considered ST to be present in two adjacent BRS. Moreover, two patients reported with BRS ST events both suffered a second ST event in the same segment. These second events were not counted.

\section{Discussion}

In this study we found that the Absorb BRS was associated with an increased incidence of definite ST compared with modern DES. We found no differences in ISR between BRS and DES. Results were consistent in magnitude and direction in all three sensitivity analyses. Our results are in line with data from randomised clinical trials and meta-analyses ${ }^{6,11-13}$. Our data on all-cause mortality and reinfarction at one year reflect markedly lower baseline risk for the BRS group compared with the DES group, and should not be misinterpreted in favour of BRS (Table 1).
This study is a complement to knowledge gained from randomised clinical trials. Our results on ST and ISR reflect the performance of the Absorb BRS device in relation to modern DES, with unrestricted use in an unselected, contemporary, real-world, complete national population. SCAAR is a high-quality registry, ideal for real-world studies on the safety of new devices. Since ST normally presents as a substantial acute myocardial infarction, it is likely to be captured in a registry-based cohort driven by clinical events.

We found a bi-phasic time distribution of Absorb BRS ST events with one cluster around the zero to six-month period followed by another cluster around the two-year mark (Figure 2A-Figure 2C). There were three cases of very late ST with the Absorb BRS, consistent with findings from randomised trials. The ABSORB Japan trial compared Absorb BRS with everolimus-eluting metallic DES (XIENCE ${ }^{\circledR}$; Abbott Vascular, Santa Clara, CA, USA) in mainly stable angina ${ }^{14}$. There was no statistically significant difference in TLF, but an excess of ST with Absorb BRS (3.1\% vs. 1.5\%), and four very late cases of ST were seen only in the Absorb BRS group (1.6\%). The ABSORB II three-year data showed that the Absorb BRS was associated with increased rates of ST $(3 \%$ vs. $0 \%$, 
$\mathrm{p}=0.03$ ). There were six cases of very late ST with the Absorb BRS compared with none in the XIENCE group ${ }^{6}$.

Recently, much effort has been directed at understanding the mechanisms behind ST with the Absorb BRS. It seems that a device-specific implantation strategy, with adequate predilation and post-dilation, adequate sizing and intravascular imaging may substantially lower the risk of $\mathrm{ST}^{15,16}$. We note that none of the Absorb BRS with subsequent ST in our study were implanted using intravascular imaging. Furthermore, three out of twelve BRS with subsequent ST were deemed undersized at re-evaluation and one was excessively post-dilated $(+0.75 \mathrm{~mm})$ with a non-compliant balloon. Inappropriate device implantation did contribute to some ST events in our cohort. However, a recent detailed summary of published intravascular imaging cases suggests only half of BRS ST cases may be avoidable by using a meticulous implantation technique, due to device-specific limitations ${ }^{17}$.

Non-adherence to DAPT guidelines was noted in six out of 12 Absorb BRS ST cases in this study. Moreover, we found three cases of very late ST, in line with randomised clinical trial signals. Future studies are warranted to look at tailoring DAPT for patients treated with BRS, possibly with a risk/benefit profile of prolonged DAPT different from that of modern DES.

To minimise inappropriate handling of the device, a controlled introduction was applied nationally in Sweden, with every physician obliged to perform three implantations in the presence of a company representative before being considered certified and free to use the device without particular safety measures. Absorb BRS in which ST occurred had been implanted mainly by very experienced physicians: nine out of 11 operators had more than 10 years' experience in PCI. Despite a cautious introduction, we identified a tendency towards lower rates of ST in the later rather than earlier devices implanted by a particular interventionist, implying a learning curve. Out of 12 ST events, eight devices had been implanted as one of the first five Absorb BRS implantations by the same operator. A remaining question is whether optimal patient selection, implantation technique and tailored DAPT duration would render outcome similar to or superior to modern DES.

\section{Limitations}

An obvious limitation is our relatively small sample size of 810 Absorb BRS devices as well as the limited number of ST and ISR events. Inherent to all registry studies, there is a risk of underreporting of events. This may be particularly true for ISR, as symptoms are not always as evident as those associated with ST. Furthermore, we only report definite ST and not probable or possible ST. There is only limited adjudication of the registry, nonspecific to this study. Selection bias may influence the outcome of Absorb BRS versus DES. Given that the Absorb BRS and DES groups are vastly different at baseline, there is probably residual bias despite adjustment with propensity scoring for known variables. However, since the Absorb BRS has been implanted in a substantially younger, lower-risk population, residual bias should if anything contribute to a relatively better outcome with
Absorb BRS compared with DES. Suboptimal BRS implantation technique in relation to current recommendations, but in accordance with the manufacturer's instructions at the time, was used and negatively affected outcome. Our analysis on device sizing was post hoc and subjective.

\section{Conclusions}

In Sweden, the Absorb BRS was implanted in a younger and considerably lower-risk population compared with modern DES. Despite this obvious and appropriate patient selection, the Absorb BRS was associated with a doubled absolute risk of definite ST at stent level and a fourfold increased adjusted risk at stent and patient level, over a mean follow-up of two years. One fourth of the observed ST events occurred later than one year after implantation. Suboptimal implantation technique and non-compliance with DAPT duration guideline recommendations were common among the reported Absorb BRS definite ST events.

\section{Impact on daily practice}

This real-world evidence, in line with clinical trial data, indicates that the current-generation Absorb BRS should not be preferred to modern drug-eluting stents in routine practice due to the associated increased risk of stent thrombosis.

\section{Acknowledgements}

The authors would like to thank all Swedish PCI operators contributing to the SCAAR. We are particularly grateful for physicians taking their time to review films for patients with Absorb BRS ST events.

\section{Funding}

Funding for this study was obtained from the National Swedish Heart and Lung Foundation, Swedish Research Council and Swedish Foundation for Strategic Research (TOTAL-AMI).

\section{Conflict of interest statement}

P. Grimfjärd reports receiving institutional research grants from The Medicines Company and lecture fees from AstraZeneca. S. James reports receiving institutional research grants from AstraZeneca, The Medicines Company, Boston Scientific and Abbott, and institutional lecture and advisory board fees from AstraZeneca, Bayer and The Medicines Company. J. Persson reports receiving speaker's honoraria from AstraZeneca, Abbott and Amgen, and an unrestricted research grant from Abbott. C. Varenhorst reports receiving institutional research grants from AstraZeneca and The Medicines Company, lecture and advisory board fees from AstraZeneca, The Medicines Company and Boehringer Ingelheim, lecture fees from Bayer, Bristol Myers Squibb, Pfizer and CSL Behring, and is on the Clinical Endpoint Committee for Pfizer, Bristol Myers Squibb, Philips and AstraZeneca. B. Lagerqvist reports receiving institutional research grants from AstraZeneca. The other authors have no conflicts of interest to declare. 


\section{References}

1. Sarno G, Lagerqvist B, Nilsson J, Frobert O, Hambraeus K, Varenhorst C, Jensen UJ, Tödt T, Götberg M, James SK. Stent thrombosis in new-generation drug-eluting stents in patients with STEMI undergoing primary PCI: a report from SCAAR. J Am Coll Cardiol. 2014;64:16-24.

2. Bønaa KH, Mannsverk J, Wiseth R, Aaberge L, Myreng Y, Nygård O, Nilsen DW, Kløw NE, Uchto M, Trovik T, Bendz B, Stavnes S, Bjørnerheim R, Larsen AI, Slette M, Steigen T, Jakobsen OJ, Bleie Ø, Fossum E, Hanssen TA, Dahl-Eriksen Ø, Njølstad I, Rasmussen K, Wilsgaard T, Nordrehaug JE; NORSTENT Investigators. Drug-Eluting or Bare-Metal Stents for Coronary Artery Disease. N Engl J Med. 2016;375:1242-52.

3. Grimfjärd P, Erlinge D, Koul S, Lagerqvist B, Svennblad B, Varenhorst C, James S. Low real-world early stent thrombosis rates in ST-elevation myocardial infarction patients and the use of bivalirudin, heparin alone or glycoprotein IIb/IIIa inhibitor treatment: A nationwide Swedish registry report. Am Heart J. 2016;176:78-82.

4. Iakovou I, Schmidt T, Bonizzoni E, Ge L, Sangiorgi GM, Stankovic G, Airoldi F, Chieffo A, Montorfano M, Carlino M, Michev I, Corvaja N, Briguori C, Gerckens U, Grube E, Colombo A. Incidence, predictors, and outcome of thrombosis after successful implantation of drug-eluting stents. JAMA. 2005;293:2126-30.

5. Chevalier B, Onuma Y, van Boven AJ, Piek JJ, Sabaté M, Helqvist S, Baumbach A, Smits PC, Kumar R, Wasungu L, Serruys PW. Randomised comparison of a bioresorbable everolimus-eluting scaffold with a metallic everolimus-eluting stent for ischaemic heart disease caused by de novo native coronary artery lesions: the 2-year clinical outcomes of the ABSORB II trial. EuroIntervention. 2016;12:1102-7.

6. Serruys PW, Chevalier B, Sotomi Y, Cequier A, Carrié D, Piek JJ, Van Boven AJ, Dominici M, Dudek D, McClean D, Helqvist S, Haude M, Reith S, de Sousa Almeida M, Campo G, Iñiguez A, Sabaté M, Windecker S, Onuma Y. Comparison of an everolimus-eluting bioresorbable scaffold with an everolimus-eluting metallic stent for the treatment of coronary artery stenosis (ABSORB II): a 3 year, randomised, controlled, single-blind, multicentre clinical trial. Lancet. 2016;388:2479-91.

7. Wykrzykowska JJ, Kraak RP, Hofma SH, van der Schaaf RJ, Arkenbout EK, IJsselmuiden AJ, Elias J, van Dongen IM, Tijssen RYG, Koch KT, Baan J Jr, Vis MM, de Winter RJ, Piek JJ, Tijssen JGP, Henriques JPS; AIDA Investigators. Bioresorbable Scaffolds versus Metallic Stents in Routine PCI. $N$ Engl J Med. 2017;376:2319-28.

8. Jernberg T, Attebring MF, Hambraeus K, Ivert T, James S, Jeppsson A, Lagerqvist B, Lindahl B, Stenestrand U, Wallentin L. The Swedish Web-system for enhancement and development of evidence-based care in heart disease evaluated according to recommended therapies (SWEDEHEART). Heart. 2010;96:1617-21.

9. Cutlip DE, Windecker S, Mehran R, Boam A, Cohen DJ, van Es GA, Steg PG, Morel MA, Mauri L, Vranckx P, McFadden E, Lansky A, Hamon M, Krucoff MW, Serruys PW; Academic Research Consortium. Clinical end points in coronary stent trials: a case for standardized definitions. Circulation. 2007;115: 2344-51.

10. Windecker S, Kolh P, Alfonso F, Collet JP, Cremer J, Falk V, Filippatos G, Hamm C, Head SJ, Jüni P, Kappetein AP, Kastrati A, Knuuti J, Landmesser U, Laufer G, Neumann FJ, Richter DJ, Schauerte P, Sousa Uva M, Stefanini GG, Taggart DP, Torracca L, Valgimigli M, Wijns W, Witkowski A. 2014 ESC/EACTS Guidelines on myocardial revascularization: The Task Force on Myocardial Revascularization of the European Society of Cardiology (ESC) and the European Association for Cardio-Thoracic Surgery (EACTS) Developed with the special contribution of the European Association of Percutaneous Cardiovascular Interventions (EAPCI). Eur Heart J. 2014;35:2541-619.

11. Onuma Y, Sotomi Y, Shiomi H, Ozaki Y, Namiki A, Yasuda S, Ueno T, Ando K, Furuya J, Igarashi K, Kozuma K, Tanabe K, Kusano H, Rapoza R, Popma JJ, Stone GW, Simonton C, Serruys PW, Kimura T. Two-year clinical, angiographic, and serial optical coherence tomographic follow-up after implantation of an everolimus-eluting bioresorbable scaffold and an everolimus-eluting metallic stent: insights from the randomised ABSORB Japan trial. EuroIntervention. 2016;12:1090-101.

12. Ellis SG, Kereiakes DJ, Metzger DC, Caputo RP, Rizik DG, Teirstein PS, Litt MR, Kini A, Kabour A, Marx SO, Popma JJ, McGreevy R, Zhang Z, Simonton C, Stone GW; ABSORB III Investigators. Everolimus-Eluting Bioresorbable Scaffolds for Coronary Artery Disease. N Engl J Med. 2015;373:1905-15.

13. Lipinski MJ, Escarcega RO, Baker NC, Benn HA, Gaglia MA, Torguson R, Waksman R. Scaffold Thrombosis After Percutaneous Coronary Intervention With ABSORB Bioresorbable Vascular Scaffold: A Systematic Review and Meta-Analysis. JACC Cardiovasc Interv. 2016;9:12-24.

14. Kimura T, Kozuma K, Tanabe K, Nakamura S, Yamane M, Muramatsu T, Saito S, Yajima J, Hagiwara N, Mitsudo K, Popma JJ, Serruys PW, Onuma Y, Ying S, Cao S, Staehr P, Cheong WF, Kusano H, Stone GW; ABSORB Japan Investigators. A randomized trial evaluating everolimus-eluting Absorb bioresorbable scaffolds vs. everolimus-eluting metallic stents in patients with coronary artery disease: ABSORB Japan. Eur Heart J. 2015;36: 3332-42.

15. Puricel S, Cuculi F, Weissner M, Schmermund A, Jamshidi P, Nyffenegger T, Binder H, Eggebrecht H, Münzel T, Cook S, Gori T. Bioresorbable Coronary Scaffold Thrombosis: Multicenter Comprehensive Analysis of Clinical Presentation, Mechanisms, and Predictors. J Am Coll Cardiol. 2016;67:921-31.

16. Tanaka A, Latib A, Kawamoto H, Jabbour R, Sato K, Miyazaki T, Naganuma T, Mangieri A, Pagnesi M, Montalto C, Chieffo A, Carlino M, Montorfano M, Colombo A. Clinical outcomes of a real-world cohort following bioresorbable vascular scaffold implantation utilising an optimised implantation strategy. EuroIntervention. 2017;12:1730-7.

17. Sotomi Y, Suwannasom P, Serruys P, Onuma Y. Possible mechanical causes of scaffold thrombosis: insights from case reports with intracoronary imaging. EuroIntervention. 2017;12:1747-56. 